\title{
EXTENDING THE PROFESSIONAL TOOLKIT: A CASE STUDY OF WORK-BASED LEARNING IN RESEARCH MANAGEMENT
}

\author{
Lesley Brook
}

\begin{abstract}
This article presents a narrative account that contextualises and captures the impact of my Master of Professional Practice research project for me, in my role as Research Projects Coordinator at Otago Polytechnic, and for my profession of research management. Narrative descriptions of research impact are used in the United Kingdom's Research Excellence Framework (Brook, 2018; Research England et al., 2019, pp. 75, 95-98), and in Australia's Engagement and Impact Assessment (Australian Research Council, 2017). Narrative accounts have also been used to construct, compare and convey meaning from the experiences of research managers working in research impact (ARMS, n.d.(a); Westerlund \& Barrett, 2020).

For my Master of Professional Practice, I undertook a work-based learning project in my role and about my institution. My research evaluated the emotional responses of 25 participants to contemporary artworks related to environmental issues which were displayed in an exhibition at my institution. This article considers the current state of my profession of research management and the specialisation of research impact practice in particular, then the contribution that my work-based learning project makes for my professional development and for research impact practice.
\end{abstract}

\section{THE PROFESSION OF RESEARCH MANAGEMENT}

Research management is an emerging professional field which has undergone considerable change in recent decades. As a result, there is no agreed set of responsibilities for the role, no agreement even on whether it is a profession yet, and no consistent nomenclature internationally (Acker et al., 2019; Agostinho et al., 2020; Bayley et al., 2018; Berman \& Pitman, 20 I0; Collinson, 2007; Derrick \& Nickson, 2014; Shelley, 2010). Despite this state of affairs, research managers can and do form their own professional identities (Acker et al., 2019; Collinson, 2007; Shelley, 2010); indeed the state of flux arguably gives them greater opportunities to develop and influence their professional identities (Acker et al., 2019).

A person's identity is their own answer to the question "who am I?", and "identity work" is the activities that people engage in that form, reinforce or influence their identity (Brown, 2015). The identities of research managers, as of other workers, can be chosen by a person for themselves or ascribed to them by others (Brown, 2015; Collinson, 2007). Research managers negotiate their identity vis-à-vis academic staff and other professional staff in their institution (Agostinho et al., 2020; Berman \& Pitman, 20I0; Collinson, 2007; Shelley, 2010). Two key factors emerge from recent literature about the identities of research managers:

I. Research managers see themselves as helping academic staff (Acker et al., 2019; Derrick \& Nickson, 2014). At Otago Polytechnic, the Research and Postgraduate Directorate, in which I work, sees researchers as our internal customers. These are mainly but not exclusively degree-teaching academic staff. 
2. Research managers serve the institution, with the result that their contribution to researchers' success is unacknowledged (Acker et al., 2019; Agostinho et al., 2020; Collinson, 2007; Derrick \& Nickson, 2014; Shelley, 2010). Our Directorate's work benefits the research reputation, academic rigour and financial position of Otago Polytechnic, which then indirectly benefits the researchers themselves.

Having a Masters or Doctorate is advantageous for the identity work of research managers, not just for the skills learned in acquiring the qualification but also for their credibility and relationships with researchers (Acker et al., 2019; Agostinho et al., 2020; Berman \& Pitman, 2010; Collinson, 2007; Derrick \& Nickson, 2014; Shelley, 20I0). Research management is becoming more professionalised. The Australasian Research Management Society (ARMS), for example, has its own conference, professional development training modules, an accreditation process, and Special Interest Groups (ARMS, n.d.(b)).

\section{WHY RESEARCH IMPACT MATTERS}

Four primary purposes for impact assessment of research in higher education and research institutions have been identified: allocation, accountability, analysis and advocacy (CSIRO, 20I8; Morgan Jones et al., 2013). The allocation of research funding is informed by prospective anticipation of the impact which the research might feasibly have, including how that might be achieved. Research impact assessment provides accountability for the use of public money, either research funding or generally for public institutions. Analysis of research impact helps maximise impact from research in the future. Research impact assessment also informs advocacy, helping researchers and institutions show what they have done and can do.

The New Zealand government is following international trends in expecting a return on its investment of research funding, a move which I have followed and supported (Brook, 2017)! After consultation, in 2019 the Ministry of Business Innovation and Employment (MBIE) released a Position Paper "The Impact of Research" which promotes robust measurement of impact based on a 'results-chain' framework. Impact is defined as "A change to the economy, society or environment, beyond contribution to knowledge and skills in research organisations" (Ministry of Business, Innovation \& Employment, 2019, p. 7).

For the Performance-Based Research Fund's Quality Evaluation round in 2018, the Tertiary Education Commission defined "Uptake and Impact," one of the range of Research Contributions recognized, as items which "provide an indication of the contribution the staff member's research has had outside of academia," and the list of examples includes "social or environmental well-being" (2018). "The 2019 review of the PerformanceBased Research Fund (PBRF) includes examining options, costs and benefits of introducing further impact measures into the PBRF" (Ministry of Business, Innovation \& Employment, 2019, p. 9).

MBIE anticipates that applying the results-chain framework will involve research institutions in the following activities:

- Articulate your institution's contribution in terms of the results-chain

- Work with MBIE towards systems that capture linkable data along the results-chain, following NZRIS [National Research Information System] common data standards

- Support researchers to plan for and increase impact from their work (Ministry of Business, Innovation \& Employment, 2019, p. II)

I I prepared a submission on behalf of Otago Polytechnic for MBIE's consultation about research impact in 2017. 
"As a steward of the research system, MBIE would like funders, researchers and research institutions to be able to confidently assess and convincingly articulate the contribution their research has made to New Zealand." (Ministry of Business, Innovation \& Employment, 2019, p. 16).

Achieving impact from our research also matters fundamentally at Otago Polytechnic because it is one of the ways in which researchers can fulfill our institution's Vision: "Our people make a better world."

\section{HOW RESEARCH IMPACT IS CHANGING RESEARCH MANAGEMENT}

As governments and other research funders increasingly expect research impact, research managers need to support researchers in their institutions to achieve and evidence impact. 'Engagement and Impact' is one of the seven 'Core Areas of Knowledge' for research managers that have been defined by the Australasian Research Management Society, the other six being: Relational, Technical, The Research Funding Cycle, Higher Degree by Research Candidature, Ethics and Integrity, and Data and Information Management (ARMS, n.d.(b); ARMS, 202I). Each Core Area of Knowledge might form separate specialised roles in research management in a large university.

My role at Otago Polytechnic encompasses a wide variety of tasks in all seven Core Areas with a particular emphasis on Engagement and Impact with and for people outside our institution. I am responsible for some outward-facing research events each year and help promote many others. I am editor of the Relevant Research magazine and raise awareness of research through social media. I maintain not only our team's webpages but also departmental research and postgraduate webpages. I have supported researchers to develop impact plans, and I run workshops and have developed resources for them to use. The professions, industries, businesses and community organisations with whom we engage are external customers for whom we hope our staff and student research has impact.

Research impact has become a specialist area for research managers internationally (Bayley \& Phipps, 2019). Those employed in research impact roles have the same issues as research managers generally, with job titles, job descriptions and professional identities, however research impact practitioners commonly experience greater precarity because fixed term roles are common if funding is dependent on grant income (Andrews et al., 2019; Lightowler \& Knight, 2013; Watermeyer \& Rowe, 2021). As a result there is no career pathway and limited investment in training and development for research impact staff (Andrews et al., 2019; Lightowler \& Knight, 2013).

It does not have to be this way. Ghent University, for example, has responded to the 'impact agenda' by establishing ten interdisciplinary consortia (IDC) which aim to achieve societal impact, with an emphasis on partnerships with non-academic stakeholders (Ghent University, 202I). An IDC Co-ordinator is associated with each consortium to drive interdisciplinary and societal impact, and, although these roles do not necessarily include any research, appointees are deemed to be high status research staff with job security and a defined career pathway (Ghent University, 2019a; Ghent University, 2019b).

Bayley and Phipps advocate for investment in 'impact literacy' for research impact practitioners, including academic researchers as well as research support staff. Impact literacy covers what, how and who: what is impact and what is evidence of impact; the "Processes and elements by which impact is achieved;" and the "Skills and people-based factors which facilitate achievement" of impact (Bayley \& Phipps, 2019). Evidence of the impact of research impact practitioners would help address the value accorded to them (Watermeyer \& Rowe, 202I). 


\section{EXTENDING MY TOOLKIT AS A RESEARCHER}

Doing my Master of Professional Practice has extended my "toolkit" as a research manager in several different ways. It has informed my understanding of the experience of our postgraduate students. Gaining a research qualification and having more published journal articles to my name will also enhance my professional identity as a non-academic staff member within a tertiary education institution, and gives me added credibility with the academic staff who are my internal customers.

I have extended my skills as a researcher, working at the intersection of many disciplines and using a methodology that was new for me (Q Methodology) in a way that has not been done before, to evaluate emotional responses to artworks after participants had experienced the original artworks. The research skills that I have developed and demonstrated in my Master's research will help me to give appropriate advice to emerging researchers at Otago Polytechnic.

I am using these improved research skills already in my role, for example informing my work on research data governance. In addition, late last year I proposed another research impact study which is now under way as part of a wider research project. I am leading a team of four School of Nursing staff to evaluate the impact of a book about rural nursing practice in New Zealand. As well as using the skills I have gained already, that project will extend me further.

\section{EXTENDING MY TOOLKIT IN RESEARCH IMPACT PRACTICE}

Bayley et al. have developed a framework of competencies for research impact practitioners (2018). By analysing four existing frameworks, they identified 80 separate competencies in 11 categories. These categories are: (I) change management; (2) communication; (3) creating, sourcing and synthesising (research) knowledge; (4) evaluating impact of knowledge transfer; (4) facilitating and negotiating; (6) leading, managing and driving knowledge transfer; (7) managing legal issues and intellectual property; (8) managing partnerships and relationships; (9) networking and engaging stakeholders; (10) training and capacity building; and (II) understanding, creating and using knowledge transfer tools, products and practices. Not all competencies will be required in all research impact practitioner roles, but this framework offers individuals "a means to develop a clearer and enhanced professional and academic identity critical skills in an increasingly professionalised domain" (Bayley et al., 2018, p. 735).

My research project for my Master of Professional Practice provided an opportunity for me to extend some of my competencies in research impact. Not all of the competencies identified by Bayley et al. were relevant. For example, my project did not include contributing to optimization of impact, being a summative evaluation of the emotional impacts. I have extended my skills in the following areas:

\section{Category: Communication}

a. Competency: Active listening, ensuring your response is tailored to the other

I met with 25 participants individually, conducting semi-structured interviews about their strongest positive and strongest negative emotional responses to the artworks. My participants also shared with me why they had particular emotional responses to the artworks, and what they thought and felt about the environment, about additional artworks and about the exhibition generally.

b. Competency: Media engagement skills

I have been interviewed about my research in a live radio show, the Arts Hub on Otago Access Radio (Forde \& Robinson, 2021).

c. Competency: Reporting and presenting knowledge

I am presenting some of my findings at a public seminar at the Dunedin School of Art. 


\section{Category: Creating, sourcing and synthesising (research) knowledge}

a. Competency: Research knowledge assessment and management: Combining organising and summarising relevant knowledge

My literature review identified interest in the contribution of art to environmental behaviour change from psychology, environmental or geographical studies, art, and sociology. Working at the intersection of the various disciplines, I have independently and critically evaluated information and ideas with a range of theoretical and empirical frameworks.

b. Competency: Capturing tacit knowledge

Q Methodology captures participants' tacit knowledge by having them sort items on a two-dimensional scale. In this study participants arranged a numbered set of 54 laminated photographs which I had taken of the artworks in the exhibition. This captured non-verbally information about the relative strength of their emotional responses, positive and negative. The strength of Q Methodology is that statistical analysis of these $\mathrm{Q}$ sorts revealed patterns in participants' emotional responses.

c. Competency: Creating new research knowledge

I also conducted semi-structured interviews, asking each participant about their strongest positive and strongest negative emotional responses (identified in the $\mathrm{Q}$ sort) and additional questions about themselves and about the exhibition. The interviews were recorded and transcribed, and participants given an opportunity to amend the transcripts.

d. Competency: Evaluating research knowledge

The interview data explained the differences between the five groups of participants that emerged from statistical analysis of the $Q$ sorts. Thematic analysis of answers to interview questions also produced rich information about the factors influencing participants' emotional responses, about how artworks can contribute to their sense of connectedness (with the environment, with other people and internally), and about how artworks could represent what participants thought and felt about environmental issues. I have interpreted and applied my findings for a range of audiences.

\section{Category: Evaluating impact of the knowledge transfer}

a. Competency: Evaluating impact of knowledge transfer strategies and approaches

The knowledge transfer strategy which I was evaluating was a public exhibition of about 60 contemporary environmental artworks by 48 different artists, held at the Dunedin School of Art.

b. Competency: Planning impact pathways

From my reading and from discussions with lead curator Bridie Lonie, I gained an understanding of how art might achieve behaviour change through emotional engagement, which informed the research design both with respect to the choice of $\mathrm{Q}$ Methodology and the questions to ask participants.

\section{Category: Managing partnerships/relationships}

a. Competency: Stakeholder communications: coordinating regular communications to link groups with information relevant to their current topic of interest

I have sent participants a link to the podcast of the radio show and will invite them to the Dunedin School of Art seminar. I will also send copies of journal articles about my research to the artists whose artworks feature in photographs accompanying those articles.

b. Competency: Developing and maintaining professional relationships

My relationship with exhibition curator Bridie Lonie has been critical to this project. I needed to do my own research but evaluate the extent to which the exhibition meets her goals for it. As this was a work-based learning project, I also needed and benefitted from my line manager's support. 


\section{Category: Networking and engaging stakeholders}

a. Competency: Making contacts with the (right) people

With ethics approval from the Capable NZ Research Ethics Committee, I engaged with visitors to the exhibition, inviting them to participate in my research. Two participants I approached afterwards, having seen them at the exhibition, and one approached me afterwards, having heard of my research project. Individual meeting times were arranged with each person at mutually convenient times and locations.

\section{Category: Understanding, creating and using knowledge transfer tools, products and practices}

a. Competency: Practical application of knowledge mobilization/knowledge transfer tools, techniques and frameworks

I described the inputs, activities, outputs, outcomes and impacts from this exhibition in a logic model. The emotional impact of the exhibition, evaluated within two weeks of the exhibition closing, is an outcome which it is hoped will support environmental behaviour change as a longer term impact.

b. Competency: Sector-specific application: applying knowledge to improve processes and outcomes in a specific field

I have learned more about how art emotionally engages viewers, which will help me to support artists and curators to achieve and to evidence impact from their creative research outputs. This will help position the Dunedin School of Art at Otago Polytechnic within a new national framework for vocational education that focuses on employers' needs rather than self-employment for graduates (Tertiary Education Commission, 202I), and within a national research system that places "a significant focus" on commercial benefits for New Zealand (Ministry of Business, Innovation and Employment, 2015).

My experience suggests that work-based learning can be an effective tool for professional development for research managers, to build impact literacy competencies.

\section{EXTENDING THE RESEARCH IMPACT TOOLKIT FOR RESEARCH MANAGERS}

Assessment of the impact of arts research is particularly challenging (Belfiore \& Bennett, 2007; Johanson \& Glow, 2015; Westerlund \& Barrett, 2020). The results of my research will inform research impact assessment internationally, by contributing to increased understanding of what impact art has and how. My research into the emotional effects of artworks contributes valuable insights because I assessed the impact of many artworks by various artists in a curated exhibition rather than of a single artwork. By shedding light on the factors influencing participants' emotional response to artworks, and how the artworks contributed to connectedness and represented their thoughts and feelings about the environment, my research improves understanding of how artworks emotionally engage and hence informs research impact planning and assessment. These results are relevant to artists, curators and arts managers as well as research managers, and are being published in other articles and conferences.

My research will also inform research impact assessment because of the novel use of Q Methodology with artworks. Q Methodology has been used with images to measure emotional responses ( $O$ 'Neill et al., 2013; Schultz et al., 20I8; Sleenhoff et al., 2015) and with statements to measure emotional responses to art (Burke et al., 2018). It has been used with images of artworks (Beck, 2017; Gauzente \& Good, 2019; Stephenson, 1936), but my research is unique in using $Q$ Methodology with images of artworks to evaluate emotional responses to artworks after participants have seen the original artworks.

One of the challenges in assessing the impact of the arts is that audience members feel a sense of responsibility to show appreciation, which makes it difficult to elicit negative responses (Johanson \& Glow, 2015). My study asked about negative as well as positive emotional responses, and revealed a difference amongst participants in 
their perception of their negative emotional responses. Boredom with some artworks was a negative emotional response, and some reported other negative emotions as a positive experience because the artworks moved them. Participants also commented negatively as well as positively when asked about the whole exhibition. My study therefore adds another valuable tool for the assessment of the impact of arts research, by demonstrating that Q Methodology can successfully be used in this context to show patterns of responses amongst participants and to elicit negative responses.

\section{CONCLUSION}

This article has focused on the impact of my work-related research project for me and for my profession of research management. My research has been a significant opportunity for professional development for me as a researcher, research manager and research impact practitioner. I have a new understanding of my profession, to which I now feel I belong. My own research makes a valuable contribution to my profession with respect to the evaluation of the impact of art research.

I have also gained a greater sense of appreciation of the value of the research ecosystem in which research managers work. This ecosystem includes researchers, for example Caro McCaw's suggestions that I submit to a particular conference, non-academic staff, for example Paula Petley who advised me about such practical matters as laminating and transcription, and other research managers like Esther de Smet at Ghent University. My learning journey as a research manager will continue with the next research impact project, which I have already embarked upon.

\section{ACKNOWLEDGEMENTS}

I would like to thank my supervisors, Martin Andrew and Glenys Forsyth, who have encouraged and challenged me as I renegotiated my professional identity. Thank you Bridie Lonie for entrusting me with this research project, and Leoni Schmidt for your support for my Master's. Thanks too to the many other members of the research ecosystem who have encouraged me.

Lesley Brook is Research Projects Coordinator in the Research and Postgraduate Directorate at Otago Polytechnic. Her research interests are in the impact of research beyond the academic community.

Email: lesley.brook@op.ac.nz

(D) https://orcid.org/0000-0001-6678-5179

\section{REFERENCES}

Acker, S., McGinn, M. K., \& Campisi, C. (2019). The work of university research administrator: Praxis and professionalization. Journal of Praxis in Higher Education, I(I), 6I-85.

Agostinho, M., Moniz Alves, C., Aresta, S., Borrego, F., Borlido-Santos, J., Cortez, J., Lima Costa, T., António Lopes, J., Moreira, S., Santos, J., Trindade, M., Varela, C., \& Vidal, S. (2020). The Interface of Science: The Case for a Broader Definition of Research Management. Perspectives: Policy and Practice in Higher Education, 24(I), 19-27. https://doi.org//0.1080/I3603 108.2018.1543215

Andrews, H., Noble, M., \& Dunleavy, K. (2019). The emergence of the publicly engaged research manager. Research for All, 3(I), 105. https://doi.org//0.18546/RFA.03.1.09 
ARMS. (n.d.(a)). 2020 Research Impact Case Studies. Retrieved May 29, 2021, from https://www.researchmanagement.org. au/2020-research-impact-case-studies

ARMS. (n.d.(b)). ARMS Professional Development. Retrieved May 29, 2021, from https://www.researchmanagement.org.au/ professional-development

ARMS. (2021). Program Guide, ARMS Foundation Level Accreditation Program. https://www.researchmanagement.org.au/ sites/default/files/uploaded-content/website-content/arms_foundation_level_accreditation_program_brochureupdated_20_april_2021.pdf

Australian Research Council. (2017). El 2018 Framework.

Bayley, J., \& Phipps, D. (2019). Building the concept of research impact literacy. Evidence \& Policy, 15(4), 597-606. https://doi. org/10.1332/174426417X15034894876108

Bayley, J., Phipps, D., Batac, M., \& Stevens, E. (2018). Development of a framework for knowledge mobilisation and impact competencies. Evidence \& Policy, 14(4), 725-738. https://doi.org//0.1332/174426417X14945838375/24

Beck, P. D. (2017). Using Works of Art to Give a Voice to Culturally Diverse Students: Q-Methodology Study. Journal for Leadership and Instruction, 16(2), 18-25.

Belfiore, E., \& Bennett, O. (2007). Determinants of Impact: Towards a Better Understanding of Encounters with the Arts. Cultural Trends, 16(3), 225-275. https://doi.org/I0.1080/09548960701479417

Berman, J., \& Pitman, T. (20।0). Occupying a 'third space': Research trained professional staff in Australian universities. Higher Education, 60(2), I57-169. https://doi.org/10.1007/s10734-009-9292-z

Brook, L. (2017). Assessing Research Impact Beyond Academia: A New Zealand Introduction. Scope (Learning \& Teaching), 3, 55-67.

Brook, L. (2018). Evidencing Impact from Art Research: Analysis of Impact Case Studies from the REF 20I4. The Journal of Arts Management, Law, and Society, 48(I), 57-69. https://doi.org/10.1080/10632921.2017.1386148

Brown, A. D. (2015). Identities and identity work in organizations. International Journal of Management Reviews, 17, 20-40, https://doi.org/10.1 III/ijmr.12035

Burke, M., Ockwell, D., \& Whitmarsh, L. (20I8). Participatory arts and affective engagement with climate change: The missing link in achieving climate compatible behaviour change? Global Environmental Change, 49, 95-105. https://doi.org/I0.1016/j. gloenvcha.2018.02.007

Collinson, J. A. (2007). "Get yourself some nice, neat, matching box files!" Research administrators and occupational identity work. Studies in Higher Education, 32(3), 295-309. https://doi.org/I0. I080/0307507070I346832

CSIRO. (20I8). How CSIRO ensures it delivers impact.

Derrick, G., \& Nickson, A. (2014). Invisible Intermediaries: A Systematic Review into The Role of Research Management in University and Institutional Research Processes. Journal of Research Administration, 45(2), II-45.

Forde, B., \& Robinson, T. (2021, April 8). Lesley Brook's Research. In Arts Hub. Otago Access Radio. https://accessmedia.nz/ Player.aspx?eid=2f3c07a0-06e8-4a08-888c-0a4d0 I4b8299

Gauzente, C., \& Good, J. M. M. (2019). Q Methodology, William Stephenson and postdisciplinarity. In T. Pernecky (Ed.), Postdisciplinary knowledge (pp. 165-182). Routledge.

Ghent University. (2019a). Portfolio for the Evaluation of IDC Co-ordinators.

Ghent University. (2019b). Regulations of Ghent University for IDC Co-ordinators.

Ghent University. (2021, May 20). Interdisciplinary research consortia aimed at realising societal impact. https://www.ugent.be/ en/research/science-society/idc/overview.htm

Johanson, K., \& Glow, H. (2015). A virtuous circle: The positive evaluation phenomenon in arts audience research. Participations: Journal of Audience \& Reception Studies, 12(I), 254-270.

Lightowler, C., \& Knight, C. (2013). Sustaining knowledge exchange and research impact in the social sciences and humanities: Investing in knowledge broker roles in UK universities. Evidence \& Policy, 9(3), 317-334. https://doi. org/l0.1332/174426413X662644

Ministry of Business, Innovation \& Employment. (2019). The Impact of Research. https://www.mbie.govt.nz/dmsdocument/6983the-impact-of-research-position-paper-october-20I9-pdf\#: :text=In\%20this\%20paper\%2C\%20MBIE\%20 introduces,stages\%20leading\%20to\%20research\%20impact

Ministry of Business, Innovation and Employment. (2015). National Statement of Science Investment 2015-2025. https://www. mbie.govt.nz/assets/2eaba48268/national-statement-science-investment-20l5-2025.pdf 
Morgan Jones, M., Castle-Clarke, S., Manville, C., Gunashekar, S., \& Grant, J. (20 I3). Assessing Research Impact: An International Review of the Excellence in Innovation for Australia Trial. RAND Europe. https://www.rand.org/pubs/research_reports/ RR278.html

O'Neill, S. J., Boykoff, M., Niemeyer, S., \& Day, S. A. (2013). On the use of imagery for climate change engagement. Global Environmental Change, 23(2), 413-421. https://doi.org/10.1016/j.gloenvcha.2012.11.006

Research England, Scottish Funding Council, Higher Education Funding Council for Wales, \& Department for the Economy, Northern Ireland. (2019). Guidance on submissions REF 2019/01.

Schultz, T., Fielding, K., \& Newton, F. (20I8). Images that Engage People with Sustainable Urban Water Management. Science Communication, 40(2), 199-227. https://doi.org/10.1177/1075547018760902

Shelley, L. (2010). Research Managers Uncovered: Changing Roles and 'Shifting Arenas' in the Academy. Higher Education Quarterly, 64(I), 4I-64. https://doi.org/I0.1 III/j.1468-2273.2009.00429.x

Sleenhoff, S., Cuppen, E., \& Osseweijer, P. (2015). Unravelling emotional viewpoints on a bio-based economy using Q methodology. Public Understanding of Science, 24(7), 858-877. https://doi.org/l0.1177/09636625/351707|

Stephenson, W. (1936). The Inverted Factor Technique. British Journal of Psychology. General Section, 26(4), 344-361. https:// doi.org/l0.1III/j.2044-8295.1936.tb00803.x

Tertiary Education Commission. (2018, April). Performance-Based Research Fund Guidelines for tertiary education organisations participating in the 2018 Quality Evaluation.

Tertiary Education Commission. (2021, March 31). Reform of Vocational Education (RoVE). https://www.tec.govt.nz/rove/ reform-of-vocational-education/

Watermeyer, R., \& Rowe, G. (202I). Public engagement professionals in a prestige economy: Ghosts in the machine. Studies in Higher Education (Dorchester-on-Thames), I-14. https://doi.org/I0.1080/03075079.2021.1888078

Westerlund, H., \& Barrett, M. (2020). Narrating arts education research impact in and through research policy: Affordances and constraints for professional transformation. Arts Education Policy Review, I-13. https://doi.org//0.1080//06329/3.2 020.1811819 